\title{
The Relationship between Bond Strength and Critical Penetration Depth of Rust in Reinforced Concrete Structures
}

\author{
Philip Mogire $^{1}$, John Mwero ${ }^{1}$, Silvester Abuodha ${ }^{1} \&$ Geoffrey Mang'uriu ${ }^{2}$ \\ ${ }^{1}$ Department of Civil and Construction Engineering,University of Nairobi, 30197-00100, Nairobi, Kenya \\ ${ }^{2}$ Department of Civil, Construction and Environmental Engineering,Jomo Kenyatta University of Agriculture \\ and Technology, 62000- 00100, Nairobi, Kenya \\ Correspondence: Philip Mogire, Department of Civil and Construction Engineering, University of Nairobi, \\ 30197,00100, Nairobi, Kenya. E-mail: philosiemo@yahoo.com
}

Received: October 27, 2021

Accepted: November 15, 2021

Online Published: November 24, 2021

doi:10.5539/jmsr.v10n2p71

URL: https://doi.org/10.5539/jmsr.v10n2p71

\begin{abstract}
Bond strength and critical penetration depth of rust are major factors that affect the service life of reinforced concrete structures. This research endevoured to establish a relationship between the bond strength and critical penetration depth of rust for reinforced concrete structures. There are 7 brands of Cem 1 cement in Kenya available for use in concrete structures. To achieve the desired objective, three Cem 1 cement brands (Cem A, B and C), fine aggregates, coarse aggregates and steel were obtained from the local Kenyan market. The chemical and physical properties of the materials were investigated. For a selected design strength of $25 \mathrm{~N} / \mathrm{mm}^{2}$, concrete materials were batched by weight and mixed by an electric pan mixer. For each brand of cement 9 cubes of size $150 \mathrm{~mm} * 150 \mathrm{~mm}$ $* 150 \mathrm{~mm}$ for a compression test, 9 cylinders of $150 \mathrm{~mm} * 300 \mathrm{~mm}$ for tensile strength and 9 cylinders of $150 \mathrm{~mm} *$ $300 \mathrm{~mm}$ for bond strength were cast. After 24 hours, the cast specimens were demoulded and immersed in curing tanks for 27 days. Specimens for compression, split tensile and bond strength were tested at 7,14 and 28 days. From the results, it was observed that the chemical composition of Cem 1 brands in the Kenyan market vary, which affects the hardening properties of concrete. A model for the critical penetration depth of rust in reinforced concrete was proposed by establishing a correlation between the spilt tensile and bond strength and substituting it in the Xu and Shayan model. The proposed and published models compared well. From the proposed model, a relationship between the critical penetration depth and bond strength was established. It was noted that the critical penetration depth increased with an increase in the bond strength of reinforced concrete. The results of this research are expected to contribute to the modeling of the service life of reinforced concrete structures.
\end{abstract}

Keywords: bond strength, cement brands, critical penetration depth

\section{Introduction}

The Kenyan Presidency (2018-2022) defined four pillars (manufacturing, affordable housing, universal health coverage and food security) for better implementation of its strategies. Cement as a construction material has a direct or indirect effect on the sustainability of the defined pillars and consequently the realization of the United Nations Sustainable Development Goals. There are $7 \mathrm{Cem} 1$ brands in Kenya manufactured by different manufacturers to cope up with the demand in the region. The brands differ in chemical composition that may affect the properties of hardened concrete, including local bond stress, split tensile and compressive strength.

The local bond stress slip behavior of reinforced concrete is a fundamental property required for the analysis and design of concrete structures at both serviceability and ultimate limit state (Sturm \& Visintim, 2018). The bond behavior of reinforced concrete structures is an interaction between reinforcing steel and concrete. It enables the transfer and compatibility of deformation between the reinforcing steel bar and the surrounding concrete (Zhao \& Lin, 2018). The bond properties have little, if any, effect on tension-stiffening but a major effect on crack parameters; spacing and width (Sturm, Visintin, \& Oehlers,2021), depth, frequency and healing (Shaikh,2018) aggravating the ingress of corrosion agents, thus affecting serviceability (Sturm, Visintin, \& Oehlers,2017). These agents, on a critical scale, will destroy the passive film on the reinforcement, after which corrosion will be initiated (Chen, Berrocal, \& Lofgren, 2020). 
Time required for concrete cover cracking is used as a service life indicator in the assessment of deterioration of corrosion-affected reinforced concrete structures (Baji \& Shi, 2020). Corrosion progression is time related and many studies have been conducted to evaluate the corrosion penetration depth (radius loss) (Chen et al., 2020). The critical penetration depth (Xcrit.) is the amount of reinforcement radius loss required to cause a crack on the surface (Mogire, Abuodha, Mwero, \& Mang'uriu, 2018). There has been an attempt to develop models for calculating the critical penetration depth of rust in reinforced concrete structures.

Torres-Acosta and Sagüés, Xu and Shayan (Hajkovaa, Smilauera, Jendeleband, \& Cervenkab, 2018, Alonso, Andrade, Rodrigues, \& Diez, 1998) developed models for the critical penetration depth of rust based on experiments. The results of these models give different outputs due to different component parameters.

The input parameters in the critical penetration depth of rust can be acquired by experiments or artificial intelligence (AI) based techniques. Within the various AI-based techniques, artificial neural networks (ANNs) and adaptive neurofuzzy inference system (ANFIS) are the most commonly used methods.

ANN method was also applied for the prediction of compressive strength for different types of concrete, such as high-strength concrete (Sobhani, Najimi, Pourkhorshidi, \& Parhizkar, 2010) and no-slump concrete (Nguyen \& Dinh, 2020). Nguyen and Dinh applied the ANFIS method to estimate the 28-day compressive strength of concrete (Armaghani, Hatzigeorgiou, Karamani, Skentou, Zoumpoulaki, \& Asteris, 2019). In a recent study, Armaghani et al. applied an ANN method to predict the shear strength of the concrete beam. To the best of the authors' knowledge, there has been no available research to apply the AI-based models for predicting the critical penetration depth of rust or bond strength of reinforced concrete. Accordingly, in this study, for a characteristic compressive strength of $25 \mathrm{~N} / \mathrm{mm}^{2}$, a series of 3 Cem 1 brands was used to prepare concrete for split tensile, compressive and bond strength. A relationship between the split tensile and bond strength has been established, which is incorporated in a proposed model for the critical penetration depth of rust.

This research proposes a model for critical penetration depth of rust by establishing a relationship between the split and bond strength of reinforced concrete and substituting it in the Xu and Shayan model. A relationship between the proposed critical penetration depth of rust and bond strength of reinforced concrete has been established. A parametric study of the critical penetration depth of rust has been done and the proposed model is compared with the published research.

This study proposes that the critical penetration depth of rust increases with an increase in bond strength. A relationship established between the critical penetration depth of rust and bond strength can be applied in calculating the corrosion initiation period in reinforced concrete structures.

\section{Method}

The study was conducted at the University of Nairobi Concrete and Materials Lab, where the physical properties of the materials were identified and the sample preparation and testing were done. The chemical properties of the selected Cem 1 brands were identified in the State Department of Infrastructure in the Ministry of Transport, Infrastructure, Housing and Urban Development of the Government of Kenya.

\subsection{Cement, Aggregates and Water for the Study}

Available Cem 1 brands of cement in Kenya are manufactured in accordance with KS EAS 18-1(2017). The cements were sourced from a local wholesaler and were randomly selected. Table 1 shows the sources of the fine aggregate(FA), coarse aggregates(CA) reinforcing steel bar and water used in this study.

Table 1. Details of material for this study

\begin{tabular}{llll}
\hline SN & Description & Source & Remark \\
\hline 1. & Fine aggregates & Machakos River & \\
2. & Coarse aggregates & Kenya Builders quarry & 5-20mm graded at source \\
3. & $10 \mathrm{~mm}$ ribbed bars & Local Manufacturer & Factory cut to 1010mm length \\
4. & Mixing water & lab & Portable \\
\hline
\end{tabular}

\subsection{Test for Mechanical Properties of Aggregates}

Table 2 shows the reference standard used for the procedure of testing aggregates the physical and mechanical properties of aggregates. 
Table 2. Testing procedure for physical and mechanical properties of aggregates

\begin{tabular}{ll}
\hline Test & Standard for test procedure \\
\hline Specific gravity & ASTM C128 \\
Water absorption & BS 812-2:1995 \\
Silt content & ASTM C142-97 \\
Crushing value & BS EN 1097-2 \\
Impact value & BS EN 1097-2 \\
Flakiness index & BS/EN 933-3 \\
Los Angeles abrasion value & BS/EN 1097-2 \\
\hline
\end{tabular}

\subsection{Mix Design}

The concrete used for this study was of characteristic strength $25 \mathrm{~N} / \mathrm{mm}^{2}$ designed according to the Department of Environment's Design (DOE) method (Ejiogu et al., 2020) and constituted the proportions shown in Table 3.

Table 3. Mix proportions of materials for this study

\begin{tabular}{lccc}
\hline Cem $1\left(\mathrm{~kg} / \mathrm{m}^{3}\right)$ & $\mathrm{FA}\left(\mathrm{kg} / \mathrm{m}^{3}\right)$ & $\mathrm{CA}\left(\mathrm{kg} / \mathrm{m}^{3}\right)$ & Water $\left(\mathrm{kg} / \mathrm{m}^{3}\right)$ \\
\hline 450 & 650 & 1190 & 225 \\
\hline
\end{tabular}

Using the mix proportions, fresh concrete was prepared by using an electric mixing pan, poured into the moulds in five layers and vibrated by a vibrating table for 60 seconds. A slump test was carried out for each batch of concrete. After 24 hours, the moulds were removed and the concrete specimens cured at normal room temperature in a water tank for 27 days.

\subsection{Size, Power, and Precision}

Cubes of size $150 \mathrm{~mm} * 150 \mathrm{~mm} * 150 \mathrm{~mm}$, cylinders with a diameter of $150 \mathrm{~mm} * 300 \mathrm{~mm}$ long, cylinders of diameter $150 \mathrm{~mm} * 30 \mathrm{~mm}$ long with $10 \mathrm{~mm}$ diameter $* 1010 \mathrm{~mm}$ long reinforcing ribbed steel bar centrally placed in line with BS 12390-1 (2012), BS EN 12390-5 (2009) and ACI 318 -08 specifications were employed to produce concrete specimens for compressive strength, tensile strength and bond strength. A total number of 27 cubes, 27 cylinder specimens for tensile strength and 27 cylinders for bond strength were prepared, cured and tested according to the methods stipulated in BS EN 12390-2 (2019), BS EN 12390-6 (2009), [20] for 7,14 and 28 days' compressive strength, tensile and bond strength. Each sample for compressive strength was subjected to loading until failure using an automated electronic testing machine, which conforms to BS EN 12390-4 (2019). A universal testing machine (UTM) maximum load of $2000 \mathrm{kN}$ was used to test the cylinders for tensile strength.

The bond strength study was carried out through a pull out test in which a manually operated hydraulic pump with a load cell of $100 \mathrm{kN}$ was used. The load was applied at a rate of $2 \mathrm{kN} / \mathrm{sec}$ and distributed on the specimen surface by a $200 \mathrm{~mm}$ square steel plate with a hole at the center system. The setup of the pull out test is shown in Figure 1. 


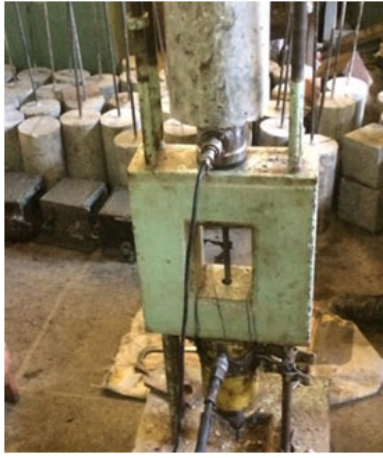

(a)Sample confining apparatus

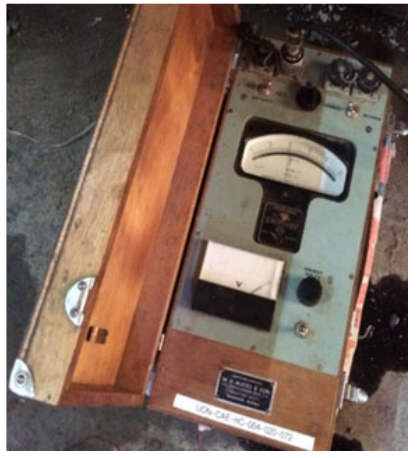

(b) Tensile load detection equipment

Figure 1. (a)- (b) Pull out Testing equipment during sample testing (Source: Author)

Bond stress (S) in MPa was calculated as average stress between the reinforcing bar and the surrounding concrete along the embedded length of the bar from Equation 1.

$$
S=\frac{P_{\max }}{\pi d_{b} L_{d}}
$$

Where $\mathrm{P}_{\max }$ was the maximum pullout load(N)), $\mathrm{d}_{\mathrm{b}}$ was diameter of the $\operatorname{bar}(\mathrm{mm})$ and $\mathrm{L}_{\mathrm{d}}$ was the embedded bar length(mm).

\subsection{The Critical Penetration Depth of Rust}

From the results of the split tensile and bond strength, a relationship was established and substituted in Equation 4 for a proposed model for critical penetration depth of rust. Other parameters adopted in the proposed model are shown in Table 4

Table 4. Parameters values for the proposed model

\begin{tabular}{lllcccc}
\hline $\mathrm{c}(\mathrm{mm})$ & $\mathrm{d}(\mathrm{mm})$ & $\mathbf{f}_{\mathbf{t}}(\mathrm{MPa})$ & $\boldsymbol{v}$ & $\boldsymbol{\beta}$ & $\mathrm{E}(\mathrm{MPa})$ & $\varphi$ \\
\hline 70 & 10 & variable & 0.2 & 2.2 & 30 & 2 \\
\hline
\end{tabular}

The results of the proposed and published models were compared. Further, a relationship between the critical penetration depth and bond strength was established.

\section{Results and Discussions}

Physical and mechanical tests on aggregates were carried out to determine their suitability for use in the study.

\subsection{Results and Discussion of Material Properties}

Water soluble chlorides ions in fine aggregates were found to be zero percent and $0.002 \%$ in coarse aggregates. The percentage of chloride is less than the maximum limit of 0.03\% as per BS EN 12620(2002) and therefore acceptable for use. High water soluble chlorides in the aggregates may aggravate the threshold available in concrete and contribute to corrosion. Table 5 shows the physical properties of the aggregates used in this study.

Table 5. Physical properties of aggregates used in the study

\begin{tabular}{lcccc}
\hline Material & Specific gravity & \% Water Absorption & \% Silt content & Max. Size $(\mathrm{mm})$ \\
\hline FA & 2.6 & 1.8 & 7.4 & 4.0 \\
CA & 2.6 & 0.3 & 0 & 20.0 \\
\hline
\end{tabular}

As seen in Table 5, the specific gravity of all the aggregates is within the limits of $2.4-3.0$ conforming to BS EN 1097-6:2013 and they influence the mix design of the concrete. The optimal concrete strength is attained when the 
specific gravity of coarse aggregates is higher than that of water and lower than that of cement. The water absorption of the fine aggregates is within the limits of $1 \%-3 \%$ in BS EN 1097-6(2013) implying a low water absorption hence being suitable for concrete works. The low water absorption in the coarse aggregates was taken into consideration in the mix design.

ASTM C117 - 17 gives an allowable limit of $10 \%$ for silt and clay content in fine aggregates for concrete production, while BS EN 12620(2013) gives an upper limit of 3\% for non-harmful fines. The silt content in the fine aggregate was more than the allowable percentage of silt content; it was washed and oven-dried before use. Table 6 shows the mechanical properties of the coarse aggregates used in this study.

Table 6. Mechanical properties of coarse aggregates

\begin{tabular}{lcc}
\hline Test & Result & Limit \\
\hline Crushing value \% & 18 & $<45$ \\
Impact Value \% & 8 & $<45$ \\
Loss Angeles Abrasion Value \% & 20 & 30 \\
\hline
\end{tabular}

The mechanical properties of aggregates cannot be improved but depend on the properties of the parent rock. The Aggregates Impact Value is less than 30\% specified in KS EAS 18-1(2017). It, therefore, follows that the Aggregates Impact Value of all the aggregates tested were very suitable for concreting works.

The particle size distribution analysis on a representative sample, as shown in Fig.2 of the course aggregates for the work, was carried out to obtain the proportions by weight of the different sizes of coarse aggregates present. The sample is well graded with a maximum aggregate size of $20 \mathrm{~mm}$. From the gradation curve, a reasonable portion falls within the gradation limits. Reasonable workability can be achieved with such aggregates without greater fines.

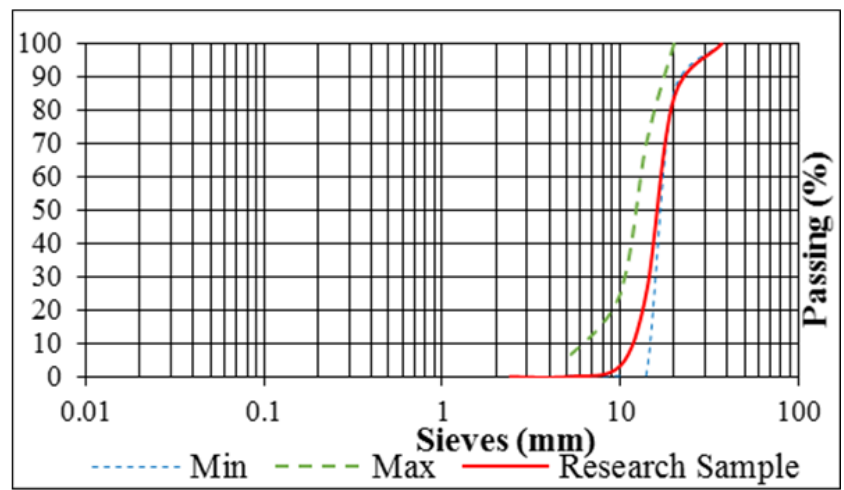

Figure 2. Gradation of Coarse aggregates

Particle size distribution analysis, as shown in Figure 3, on a representative sample of the fine aggregates for the research was carried out to obtain the proportions by weight of the different sizes of fine particles present according to BS EN 933-1(2012). The proportions were expressed as percentages by weight passing various sieve sizes conforming to BS 410. As shown in Figure 3, the fine aggregates were well graded and expected to give a well interlocked composite concrete mix. 


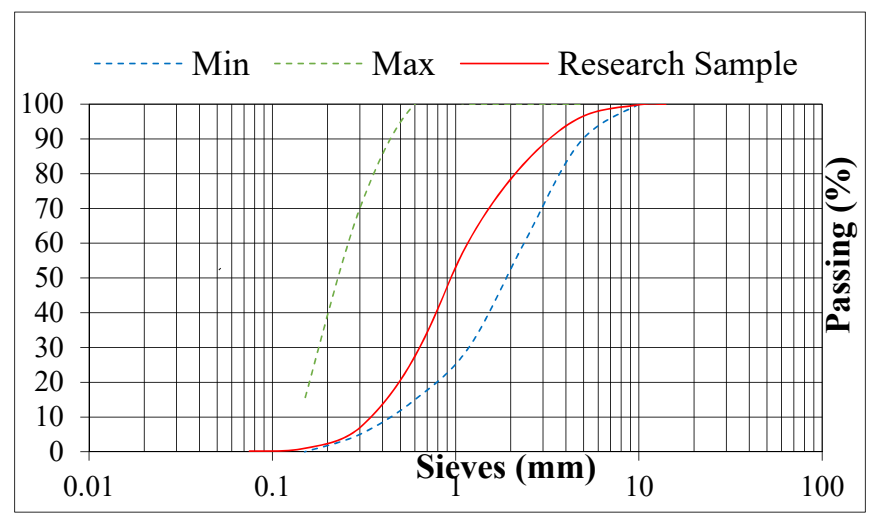

Figure 3. Gradation of fine aggregates

Table 7 shows the chemical properties of the selected Cem 1 brands in Kenya used in this study.

Table 7. Chemical composition of the cement used in the study

\begin{tabular}{lcccc}
\hline \multirow{2}{*}{ Test } & \multicolumn{3}{c}{ Result } & $\begin{array}{c}\text { KS EAS 18-1: 2017 } \\
\text { Requirement }\end{array}$ \\
\cline { 2 - 4 } $\mathrm{CaO} \%$ & Cem A & Cem B & Cem C & Sum $\geq 50$ \\
$\mathrm{SiO}_{2} \%$ & 59.86 & 59.11 & 58.82 & \\
$\mathrm{SO}_{3} \%$ & 16.56 & 21.56 & 19.47 & $\leq 3.5$ \\
$\mathrm{MgO} \%$ & 2.02 & 2.78 & 2.03 & $\leq 5$ \\
$\mathrm{~K}_{2} \mathrm{O} \%$ & 1.76 & 1.04 & 0.57 & \\
$\mathrm{Fe}_{2} \mathrm{O}_{3} \%$ & 0.027 & 0.051 & - & $3-8$ \\
$\mathrm{Al}_{2} \mathrm{O}_{3}$ & 2.32 & 3.48 & 1.44 & \\
$\mathrm{Na}_{2} \mathrm{O}_{3} \%$ & 7.61 & 8.09 & 6.85 & $\leq 5$ \\
$\mathrm{LOI}^{2} \%$ & 0.054 & 0.018 & & $\leq 0.1$ \\
$\mathrm{Cl} \%$ & 0.11 & 0.10 & 4.75 & $\leq 5$ \\
$\mathrm{IR} \%$ & 0.012 & 0.016 & 0.014 & \\
\hline
\end{tabular}

From Table 7, Cem A has the highest amount of lime(CaO) (59.86\%) and Insoluble residue (2.20\%), Cem B has the highest Silicon dioxide $\left(\mathrm{SiO}_{2}\right)(21.56 \%)$. The increased sum of $(\mathrm{CaO})$ and $\left(\mathrm{SiO}_{2}\right)$ increases compressive strength and subsequently, bond strength and critical penetration depth should not be less than $50 \%$. Similarly, an increase in insoluble residue reduces compressive strength. All cement samples used for this work satisfied this requirement of KS EAS 18-1(2017). Cement sample $\mathrm{B}$ has a $\mathrm{CaO}+\mathrm{SiO}_{2}$ value of $80.67 \%$ and produced the highest compressive strength of concrete $\left(44.89 \mathrm{~N} / \mathrm{mm}^{2}\right) . \mathrm{SiO}_{2}$ has to be limited relative to $\mathrm{CaO}$ in order not to negatively affect setting time.

The ratio $(\mathrm{CaO}) /\left(\mathrm{SiO}_{2}\right)$ contents in Cem 1 cement should be greater than 2 . The restriction is to ensure that the setting of concrete is not inhibited. All the cement samples investigated fulfilled this requirement. The ratio of $\mathrm{CaO} / \mathrm{SiO} 2$ in interaction with an insoluble residue of cement influences the compressive strength.

The quantity of magnesium oxide $(\mathrm{MgO})$ in Cem 1 cement should not exceed 5\%. All the cement samples satisfied this requirement with $1.76 \%, 1.04 \%$ and $0.57 \%$ for cement samples $\mathrm{A}, \mathrm{B}$ and $\mathrm{C}$, respectively. $\mathrm{MgO}$ contributes to the colour of cement and hardness of the resulting concrete. If the quantity of $\mathrm{MgO}$ is more than $5 \%$, cracks will appear in concrete, which may reduce the bond strength by reducing the effective length. Cracks may subsequently increase and accelerate the critical penetration depth. 
The chloride content in ordinary Portland cement should be less than $0.4 \%$. All the cement samples in this work satisfied this requirement. Chloride content limits ensure a reduced amount available to aggravate corrosion, which in turn reduces bond strength.

$\mathrm{Na} 2 \mathrm{O}, \mathrm{K}_{2} \mathrm{O}, \mathrm{TiO}_{2}$ and $\mathrm{P}_{2} \mathrm{O}_{5}$ in Cem 1 are considered residues and their sum is limited to $5 \%$ (Sharma,2020). All the cement samples investigated fulfilled this requirement, with cement samples A, B and C having total residue contents of $0.55,2.2$ and $1.96 \%$, respectively. If these values are more than $5 \%$, efflorescence and unsightly cracking will occur, thus reducing the bond strength.

\subsection{Results of Fresh Concrete Test}

The result for the slump test of the fresh concrete is shown in Figure 4. The slumps obtained are in the medium range (68-93mm).

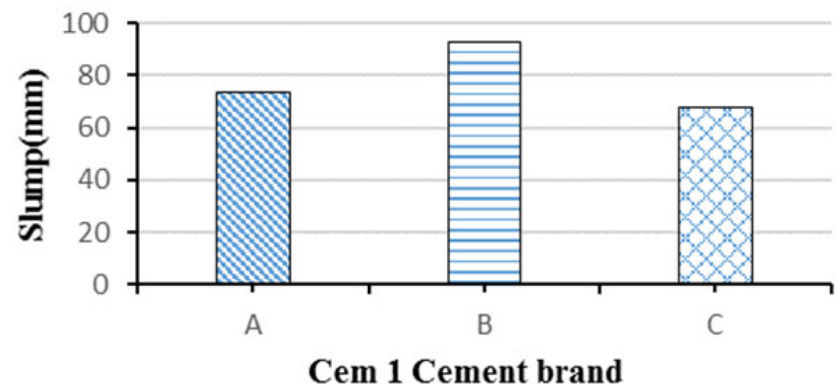

Figure 4. Slump from Cem 1 brands of cement

From Figure 4, concrete with Cem B brand of cement had the highest slump while C had the lowest slump. Workability increases with an increase in a slump and this reduces the resulting strength on concrete.

\subsection{Results of Hardened Concrete}

Table 8 shows the compressive, split tensile and bond strength results.

Table 8. Results of properties of hardened concrete

\begin{tabular}{lccc}
\hline Cem 1 brand & Compressive strength $\left(\mathrm{N} / \mathrm{mm}^{2}\right.$ & Tensile strength $\left(\mathrm{N} / \mathrm{mm}^{2}\right)$ & Bond strength $\left(\mathrm{N} / \mathrm{mm}^{2}\right)$ \\
\hline A & 41.29 & 4.5 & 4.42 \\
B & 41.09 & 4.45 & 4.33 \\
C & 44.89 & 4.48 & 4.4 \\
\hline
\end{tabular}

From Table 8, Figures 5, 6 and 7 are drawn to show the relationship of the hardened properties of concrete for a selected brand of cement. Fig. 5 shows a bar chart of a comparative relationship of the hardened properties of concrete with a selected Cem 1 brand. 


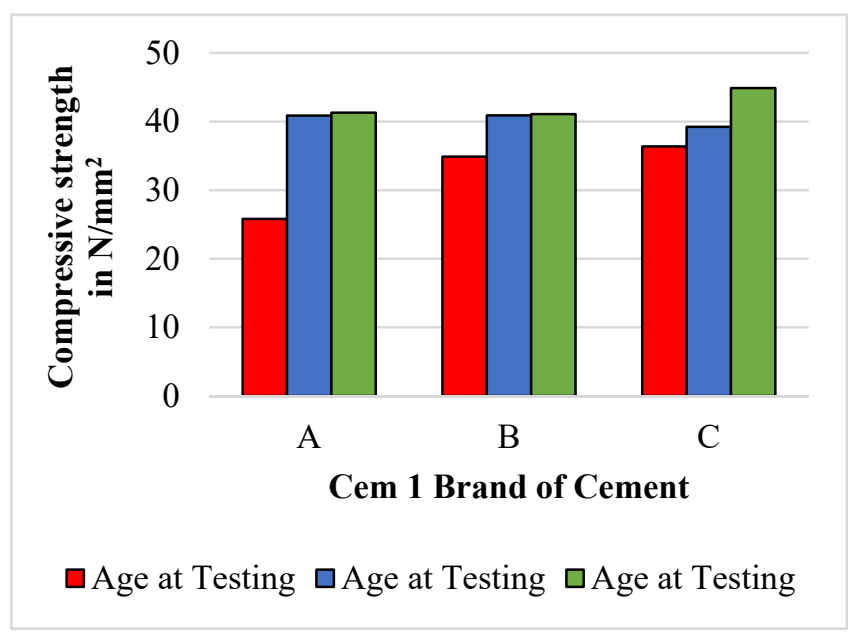

Figure 5. Bar chart of Compressive strength for selected Cem 1 Cement brand

From Figure 5, it can be noted that a choice of a brand of Cem 1 cement influences the compressive strength. As expected, $\mathrm{Cem} \mathrm{C}$ with the highest $\mathrm{CaO} / \mathrm{SiO}_{2}$ ratio in interaction with insoluble residue had the highest compressive strength. A high compressive strength increases bond strength and affects the critical penetration depth. This result is also in line with those from Fig.3, as increase in slumps causes reduced strength, durability and permeability of concrete. The test was carried out after 27 days of curing.

Figure 6 shows a bar chart of the relationship of split tensile strength and a selected Cem 1 brand of cement as shown in Table 8.

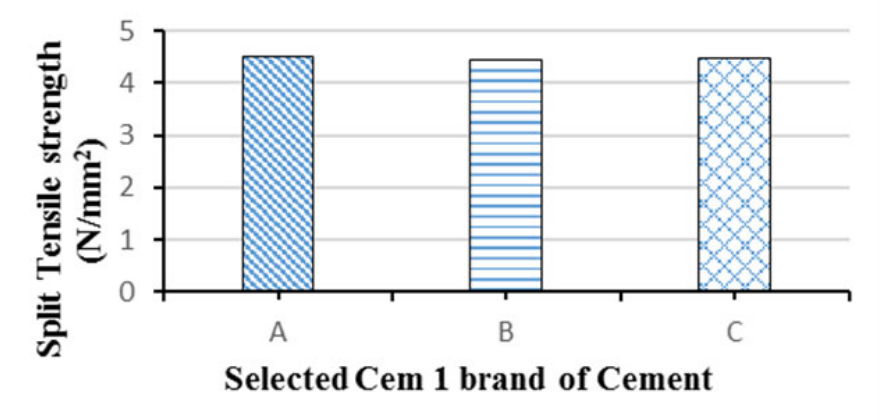

Figure 6. Bar Chart showing the relationship of split tensile strength of concrete with selected Cem 1 brands of cement.

From Figure 6, it can be shown that concrete with Cem $\mathrm{C}$ has the highest split tensile strength. Cem $\mathrm{C}$ has the highest $\mathrm{CaO} / \mathrm{SiO}_{2}$ ratio in combination with insoluble residue and increases the compressive strength and subsequently the split tensile strength. Figure 7 shows a relationship between bond strength and a brand of Cem 1 cement. 


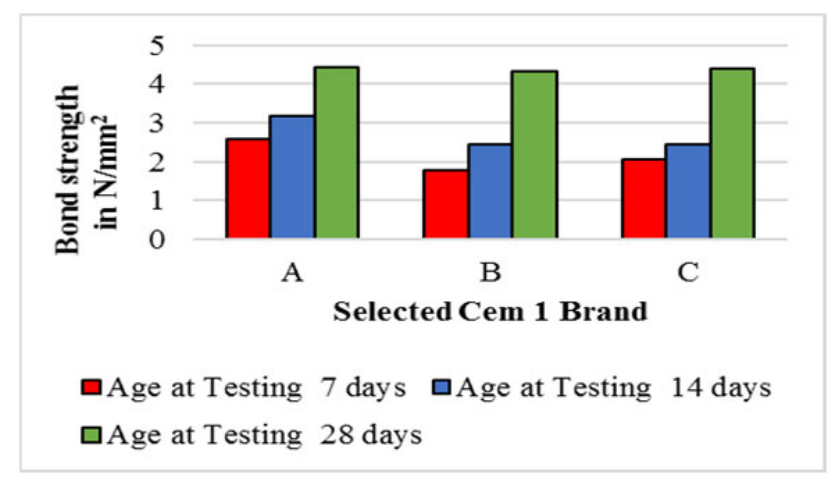

Figure 7. Relationship of bond strength and selected Cem 1 cement brand

From Figure 7, a selected Cem 1 cement brand influenced the bond strength of the reinforced concrete samples. Samples with Cem B brand of cement had the lowest chemical constituents that affect compressive strength and subsequently had the lowest bond strength as expected.

Based on the results shown in Figure 7, the choice of Cem 1 brand of cement significantly affects the bond strength and subsequently the service life of the respective structures.

Table 9 shows a statistical relationship between split tensile and bond strength in a linear regression statistical model with a $96.2 \%$ coefficient of determination.

Table 9. Statistical relationship between tensile and bond strength

\begin{tabular}{lcccc}
\hline R Squire & F & Sig & Constant & b1 \\
\hline 0.962 & 25.21 & 0.124 & 2.187 & 0.522 \\
\hline
\end{tabular}

From Table 9, Equation 2 is proposed for this study.

$$
\mathrm{ft}=2.187+0.522 \mathrm{f}_{\mathrm{b}}
$$

Where $\mathrm{f}_{\mathrm{b}}$ is the bond strength (MPa).

\subsection{Result of the Critical Penetration Test}

This section discusses and analyses the published models for evaluating the critical penetration depth of rust. It also compares them with the proposed model. Torres-Acosta and Sagüés (Hajikova et al., 2018) proposed Equation 3 when corrosion is localized to a short length.

$$
\mathrm{Xcrit} / \mathrm{mm} \approx 0.011\left(\frac{\mathrm{C}}{d}\right)\left(\frac{\mathrm{C}}{\mathrm{L}}+1\right)
$$

Where $\mathrm{C}$ is the cover depth $(\mathrm{mm})$ of concrete, $\mathrm{d}$ is diameter $(\mathrm{mm})$ of the reinforcement and $\mathrm{L}(\mathrm{mm})$ is the uniformly corroding segment lenth.

Their application cannot be extrapolated to include intersections of the rebar with preexisting cracks and does not take into account the tensile properties of concrete.

Alonso et al. (1998) showed that the corrosion loss required to generate the first visible crack is linearly proportional to the cover-rebar diameter ratio (c/d) in Equation 4.

$$
\mathrm{x}_{\text {crit }}=7.53+9.32 \frac{\mathrm{c}}{\mathrm{d}}
$$

Where $\mathrm{x}_{\text {crit }}$ is corrosion loss at crack initiation in $\mu \mathrm{m}, \mathrm{c}$ is concrete cover in $\mathrm{mm}$ and $\mathrm{d}$ is bar diameter in $\mathrm{mm}$.

Equation 4 was derived on the assumption that general corrosion in steel will cause the concrete to crack, and in cases when corrosion is limited to small locations, such as when corrosion occurs at damaged sites of epoxy-coated bars, it cannot predict the critical corrosion loss. 
$\mathrm{Xu}$ and Shayan (2016) considered the combination of concrete cover and its embedded steel as a thick-wall concrete cylinder which surrounds the embedded steel. The expansion of corroded steel exerted an internal pressure on the concrete cylinder. They derived Equation 5 for the attack penetration depth.

$$
\mathrm{x}_{\text {crit }}=\frac{\mathrm{f}_{\mathrm{t}} c(\mathrm{c}+\mathrm{d})(1+v)}{\mathrm{E}_{\text {eff }} \mathrm{d} \beta}
$$

Where $\mathrm{x}_{\text {crit }}$ is the attack penetration or the decrease in the reinforcing bar radius $(\mu \mathrm{m}), \mathrm{c}$ is the concrete cover $(\mathrm{mm})$, $\mathrm{d}$ is the bar diameter $(\mathrm{mm})$, is concrete poison's ratio, is the relative volume change $(\Delta \mathrm{V} / \mathrm{V}$ steel $)$ due to conversion of steel to rust, is the effective elastic modulus (MPa) equal to $\mathrm{E} /(1+\varphi), \mathrm{E}$ is the elastic modulus(MPa) and $\varphi$ is the creep coefficient of concrete.

From their model, the predicted critical corrosion loss was found to be four times or greater as much as the calculated values based on the measured corrosion rates from Linear Polarization Resistance (LPR) test in their research. This is because in calculating corrosion loss from the LPR test, it is assumed that the whole surface area subjected to corrosion is corroding. This is not true for non-uniform corrosion and, therefore, the calculated corrosion loss from LPR tests should be modified based on the actual corroded area of the embedded steel to present the real values.

Substituting Equation 2 into Equation 5 for the tensile strength results to Equation 6 for a proposed model for the critical penetration depth of rust.

$$
\mathrm{X}_{\text {crit }}=\frac{c(\mathrm{c}+\mathrm{d})(1+v)\left(2.187+0.522 f_{b}\right)}{\mathrm{E}_{\text {eff }} \mathrm{d} \beta}
$$

Table 10 shows a comparative study of the output of this work and published research for critical penetration depth of rust.

\begin{tabular}{|c|c|c|c|c|}
\hline Bond strength(MPa) & Critical pene & depth of rust in $\mathrm{mm}$ & & \\
\hline & This work & $\mathrm{Xu}$ and Shayan(2016) & Alonso et al(1998) & Acosta et al \\
\hline 4.33 & 0.136 & 0.136 & 0.0728 & 0.096 \\
\hline 4.4 & 0.137 & 0.137 & 0.0728 & 0.096 \\
\hline 4.42 & 0.137 & 0.137 & 0.0728 & 0.096 \\
\hline
\end{tabular}

Table 10. Relationship of the proposed and published work for critical penetration depth of rust

From Table 10, it can be shown that the proposed and published models compares well.

Figure 8 shows the relationship between the critical penetration depth of rust from the proposed model and the bond strength of reinforced concrete

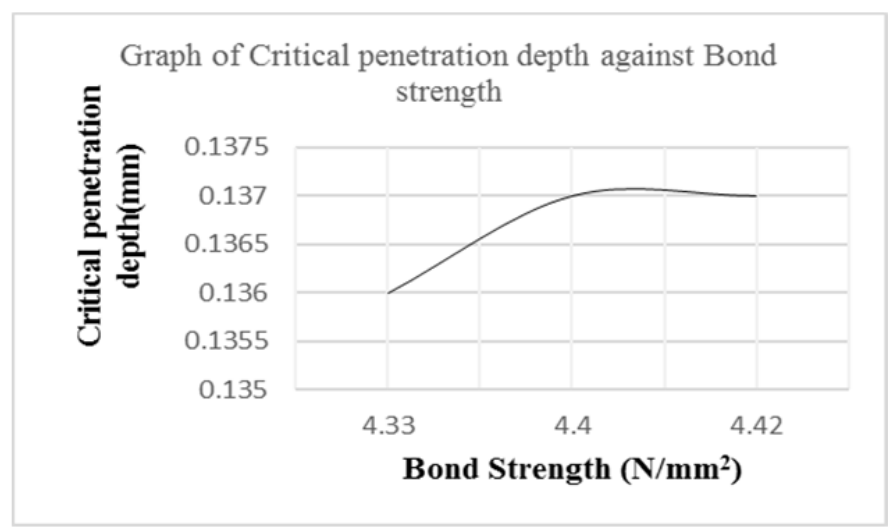

Figure 8. Relationship between critical penetration depth and bond strength of reinforced concrete 
From Figure 8, it can be shown that the critical penetration depth increases with an increase in bond strength. The use of a selected cem 1 brand of cement affects compressive, split tensile and bond strength, as shown in Figures 5 , 6 and 7. This shows that the concrete properties that affect bond strength, including compressive strength and split tensile strength, will affect critical penetration depth. The magnitude of these hardened properties of concrete continue to increase with an increase in the curing period beyond 27 days because of continuous hydration of cement. The increment is significantly small to alter the output of this work.

\section{Conclusion}

A study of selected Cem 1 brands of cement intended for structural applications has been done in this research. The variation in the chemical composition of the selected brands affects the compressive, split tensile, bond strength and critical penetration depth. According to the analyses and experiments of hardened properties of the tested samples, it was found that available Cem 1 brands of cement in the Kenyan market vary in chemical composition, and this affects the hardened properties of concrete.

It can also be deduced that the critical penetration depth of rust in reinforced concrete increases with an increase in bond strength, and this is attributed to all the factors that affect the spilt tensile strength, which subsequently affects both properties. The relationship between the critical penetration depth of rust and the bond strength established in this study can be used in the calculation of the initiation period of the service life of reinforced concrete structures. The results obtained are applicable to reinforced concrete of characteristic strength $25 \mathrm{~N} / \mathrm{mm}^{2}$. Further study of the relationship between split tensile and bond strength in higher characteristic strength is proposed.

\section{Nomenclature}

\begin{tabular}{lll}
$a_{1} \quad$ parameter $=7.44 \mathrm{e}^{-5} \mathrm{~m}$ & \\
$a_{2} \quad$ parameter $=7.30 \mathrm{e}^{-6} \mathrm{~m}$ & \\
$a_{3} \quad$ parameter $=-1.74 \mathrm{e}^{-5} \mathrm{~m} / \mathrm{MPa}$ & \\
$A_{f} \quad$ fractional corroding area relative to that of the entire rebar & $\mathrm{mm}^{2}$ \\
$c \quad$ concrete cover & $\mathrm{mm}$ \\
$C \quad$ concrete cover & $\mathrm{m}$ \\
$d \quad$ bar diameter & $\mathrm{mm}$ \\
$d_{\text {ini }}$ & initial bar diameter & $\mathrm{m}$ \\
$E$ & elastic modulus & $\mathrm{Nmm}$ \\
$E_{\text {eff }}$ & effective elastic modulus $=\mathrm{E} /(1+\phi)$ & $\mathrm{Nmm}$ \\
$f_{t}$ & concrete tensile strength & $\mathrm{MPa}$ \\
$f b$ & concrete bond strength & $\mathrm{MPa}$ \\
$f_{t . c h}$ & the characteristic splitting tensile strength of concrete & $\mathrm{MPa}$ \\
$\mathrm{L}$ & length of uniformly corroding segment & $\mathrm{mm}$ \\
$\mathrm{L}_{\mathrm{f}}$ & fractional corroding length relative to the entire bar & $\mathrm{mm}$ \\
$\mathrm{x}_{\text {crit }}$ & critical radius loss & $\mu \mathrm{m}$ \\
$\beta$ & relative volume change due to conversion of steel to rust $=(\Delta V / V)$ \\
$\phi$ & concrete creep coefficient & \\
$v$ & concrete poison's ratio & \\
\hline
\end{tabular}

\section{Conflict of Interests}

The authors declare that there is no conflict of interests regarding the publication of this paper.

\section{References}

ACI 318-08. Building Code Requirements for Structural Concrete and Commentary. American Concrete Institute, U.S.A.

Alonso, C., Andrade, J., Rodrigues, \& Diez, J. M. (1998). Factors Controlling Cracking of Concrete Affected by Reinforcement Corrosion. Materials and Structures, 31(211), 435-441. https://doi.org/10.1007/BF02480466 
Armaghani, D. J., Hatzigeorgiou G. D., Karamani, C., Skentou, A., Zoumpoulaki, I., \& Asteris, P. G. (2019). Soft computing-based techniques for concrete beams shear strength. Procedia Structural Integrity, 17, 924-933. https://doi.org/10.1016/j.prostr.2019.08.123

ASTM C117 - 17. Standard Test Method for Materials Finer than 75- $\mu$ m (No. 200). Sieve in Mineral Aggregates by washing, ASTM International. U.S.A. https://www.astm.org/Standards/C117.

Baji, H., Yang, \& Shi, W. (2020). A Probabilistic Model for Time to Cover Cracking Due to Corrosion. Structural Concrete, 21, 12. https://doi.org/10.1002/suco.201900341

British Standard Institute. (2009). BS EN 12390-6:2009: Testing hardened concrete: Tensile splitting strength of test specimen. BSI

British Standard Institute. (2012). BS EN 933-1:2012: Tests for geometrical properties of aggregates - Part 1: Determination of particle size distribution - Sieving method, Tests for mechanical and physical properties of aggregates. BSI.

British Standard Institute. (2013). BS EN 1097-6:2013: Determination of particle density and water absorption. BSI

British Standard Institute. (2013). BS EN 12620:2013: Aggregates for concrete. BSI.

British Standard Institute. (2019). BS EN 12390-3:2019: Testing hardened concrete: Shape, dimensions and other requirements for specimens and moulds, Testing hardened concrete - Part 3: Compressive strength of test specimens. BSI.

British Standard Institute. (2019). BS EN 12390-4:2019: Compressive strength, Specification for testing machines. BSI.

Chen, E., Berrocal, C. G., Löfgren, I., \& Lundgren, K. (2020). Correlation between concrete cracks and corrosion characteristics of steel reinforcement in pre-cracked plain and fibre-reinforced concrete beams. Mater Struct., 53, 33. https://doi.org/10.1617/s11527-020-01466-z

Ejiogu I. K., Mamza, P. A. P., Nkeonye, P. O., \& Yaro, S. S. (2020). Comparison of ACI, IS and DOE methods of concrete mix design, NJE, 27(1), 68-83.

Hájkováa, K., Šmilauera, V., Jendeleband, L., \& Červenkab, J. (2018). Prediction of reinforcement corrosion due to chloride ingress and its effects on serviceability. Engineering Structures, 174, 768-777. https://doi.org/10.1016/j.engstruct.2018.08.006

Kenya Standard. (2017). KS EAS 18-1:2017: Cement-Part 1: Composition, specification and conformity criteria for common cements. KS.

Mishra, A. K., Kumar, R., \& Aithal, S. (2020). Economic Operation of Cement: A Case of Gautam Buddha Airport Upgrading Component Project. International Journal of Applied Engineering and Management, 4(2). https://doi.org/10.5281/zenodo.4108233

Mogire, P., Abuodha, S., Mwero, J., \& Mang'uriu, G. (2018). The effect of Selected Cement Brands in Kenya on the Critical Penetration Depth of Rust in Reinforced Concrete Water Conveyancing Structures. International Journal of Scientific and Research Publications, 8(11), 8333. https://doi.org/10.29322/IJSRP.8.11. 2018.p8333

Nguyen, T. T., \& Dinh, K. (2020). An artificial intelligence approach for concrete hardened property estimation. Journal of Science and Technology in Civil Engineering, 14(2), 40-52. https://doi.org/10.31814/stce.nuce2020-14(2)-04

Shaikh, F. U. A. (2018). Effect of Cracking on Corrosion of Steel in Concrete. Int, J. Concr Struct Mater, 12. https://doi.org/10.1186/s40069-018-0234-y.

Sharma, M. (2020). Seismic potential parameter of concrete gravity dam. Conference: Recent trend in Civil Engineering. https://doi.org/10.13140/RG.2.2.28803.45600

Sobhani, J., Najimi, M., Pourkhorshidi, R. A., \& Parhizkar, T. (2010). Prediction of the compressive strength of no-slump concrete: a comparative study of regression, neural network and anfis models. Construction and Building Materials, 24(5), 709-718. https://doi.org/10.1016/j.conbuildmat.2009.10.037

Sturm, A. B., \& Visintin, P. (2018). Local bond slip behavior of steel reinforcing bars embedded in ultra-high performance fibre reinforced concrete. Structural Concrete. https://doi.org/10.1002/suco.201700149 
Sturm, A. B., Visintin, P., \& Oehlers, D. J. (2017). Time-dependent serviceability behavior of reinforced concrete beams: Partial interaction tension stiffening mechanics. Structural Concrete, 19(5), 33. https://doi.org/10.1617/s11527-020-01466-z

Sturm, A. B., Visintin, P., \& Oehlers, D. J. (2021). Mechanics of Shear Failure in Fiber-Reinforced Concrete Beams. Journal of Structural Engineering, 147, 3. https://doi.org/10.1061/(ASCE)ST.1943-541X.0002934

Xu, A., \& Shayan, A. (2016). Relationship between Reinforcing Bar Corrosion and Concrete Cracking. Aci Materials Journal, 113(1). https://doi.org/10.14359/51688460

Zhao, Y., \& Lin, H. (2018). The bond Behaviour between Concrete and Corroded Reinforcement: State of the Art, in 2018. Sixth International Conference on Durability of Concrete Structures, University of Leeds, United Kinddom.

\section{Copyrights}

Copyright for this article is retained by the author(s), with first publication rights granted to the journal.

This is an open-access article distributed under the terms and conditions of the Creative Commons Attribution license (http://creativecommons.org/licenses/by/4.0/). 